\title{
The Collapse Analysis of A Transmission Tower Under Wind Excitation
}

\author{
Li Tian $^{1}{ }^{1}$, Qiqi $\mathrm{Yu}^{1}$, Ruisheng Ma ${ }^{1}$ and Chengwu Wang ${ }^{2}$ \\ ${ }^{1}$ School of Civil and Hydraulic Engineering, Shandong University, Jinan, Shandong, 250061, China \\ ${ }^{2}$ Faculty of Architecture and Civil Engineering, Huaiyin Institute of Technology, Huaian, Jiangsu, 223001, China
}

\begin{abstract}
The collapse of a transmission tower under wind action is studied in this paper. A three-dimensional finite element model of the transmission tower is established based on a real project. The birth-to-death element technique is adopted in ABAQUS/Explicit. Kaimal fluctuating wind power spectrum and the harmony superposition method are used to simulate the fluctuating wind speed time history. The dynamic behavior and the collapse mechanism of the transmission tower under three different angles of attack $\alpha=0^{\circ}, 45^{\circ}$ and $90^{\circ}$ are carried out, respectively. The results show that the collapse of the transmission tower at $45^{\circ}$ angle of attack occurs easily, but it is contrary at $90^{\circ}$ angle of attack. The fracture position of the transmission tower under wind excitation is obtained, and the initial damage of the members happens simultaneously in the main and the secondary element. The results of the collapse analysis can provide reference to the design of the transmission tower and the reinforcement of this structure to prevent the collapse of the tower.
\end{abstract}

Keywords: Angle of attack, collapse analysis, collapse mechanism, fluctuating wind speed, transmission tower.

\section{INTRODUCTION}

With the development of the economic, science and technology, the development of the power system has become an inevitable trend [1]. Transmission line is an important lifeline project which can carry electric power, and its safety affects the national economy and people's life. Compared with other building structures, transmission tower has some unique characteristics: high-rise tower, huge massive structural flexibility and the sensitivity of wind load. The collapse of transmission tower has usually occurred in recent years. For example, in 2007, many transmission towers damaged seriously because of the strong wind in Liaoning province of China. During 2010, five transmission towers collapsed due to the strong wind and rain in Guangdong province of China. In 2013, many transmission towers collapsed and power facilities destroyed by the typhoon Fitow in Zhejiang province of China. Fig. (1) shows the picture of the collapse of the transmission tower under wind excitation. It can be seen from failure cases that the collapse of the transmission tower often leads to huge losses. Therefore, it is very important to study the wind resistance performance of transmission tower.

In the past decades, the wind vibration responses of transmission tower-line system were carried out. Battista et al. [2] established the finite element analysis model of the transmission tower-line system and studied the dynamic response and stability of the transmission tower line system

\footnotetext{
*Address correspondence to this author at the School of Civil and Hydraulic Engineering, Shandong University, Jinan, Shandong, 250061, China; Tel: +86 531-88396182; Fax:+86 531-88392843;

E-mail: tianl-007@163.com
}

in time domain and frequency domain under wind action. Okamura et al. [3] obtained the wind characteristics and the wind response of power transmission tower in mountainous area by full-scale measurements and investigated the flow around a two-dimensional mountain by wind tunnel tests. Finally, the wind response analysis of a transmission tower was conducted and the results were compared with measurements. Zhang et al. [4] investigated the dynamic response of the finite element model of the transmission tower-line system with ANSYS based on the background of a $500 \mathrm{kV}$ transmission line tower. Yan et al. [5] discussed the influence of the insulator wire length, initial stress and transmission tower span on vibration response of the transmission tower line system by nonlinear dynamic time history, respectively. Li et al. [6] established 3-D finite element models of single tower, one tower and two spans of conductor wires, three towers and four spans of conductor wires to research the effect of the tower-line interaction on the transmission tower-line system. Mara et al. [7] studied the dynamic response of a self-supported lattice transmission tower under traditional atmospheric boundary layer wind and downburst wind, and investigated the effect of wind direction on transmission tower. Tian et al. [8] investigated the progressive collapse process of a transmission tower under earthquake excitation by ABAQUS based on a practical engineering. Wang et al. [9] proposed a progressive collapse analytical procedure for transmission tower-line system and studied the collapse analysis of the system under strong earthquake by using the coded subroutine VUMAT and ABAQUS. The results showed that the collapse processes of the tower along longitudinal and lateral direction, and the influences of fracture strain and strain rate effect of material on collapse routine and collapse capacity were investigated. However, there are few researches about the collapse of transmission tower under wind excitation. 

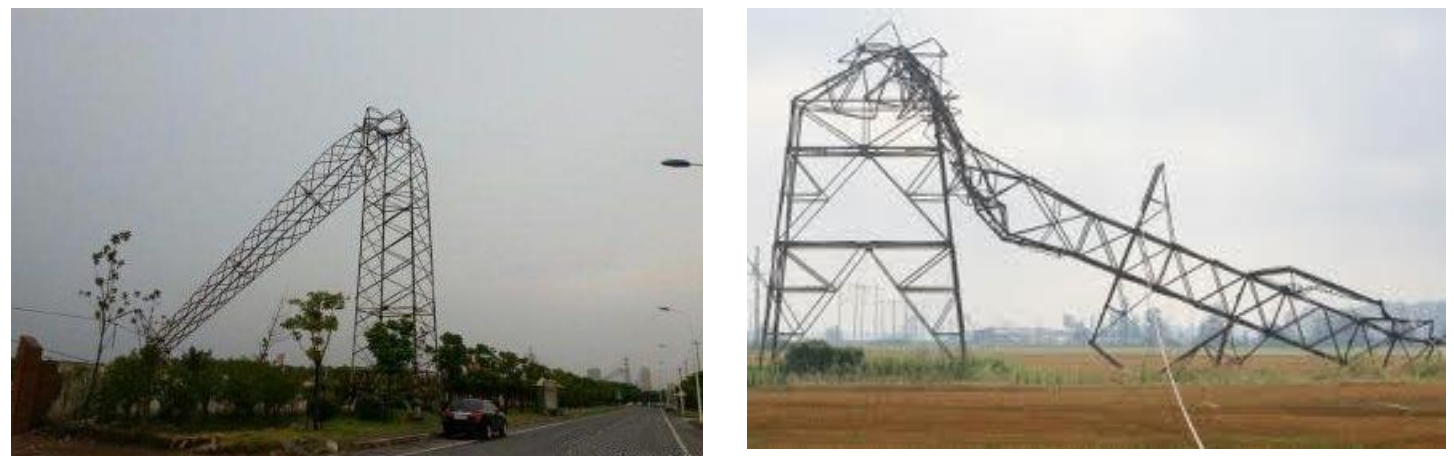

Fig. (1). The picture of the collapse of the transmission tower under wind excitation.

The progressive collapse performance of a transmission tower is investigated in this paper. The three-dimensional element model is created based on a real project with ABAQUS software. Birth-to-death element method is used to simulate the collapse process of the transmission tower. The collapse mode, collapse mechanism and collapse resistant capacity of the transmission tower can be obtained by collapse analysis.

\section{COLLAPSE ANALYSIS METHOD}

\subsection{Birth-to-death Element}

The simulation of birth-to-death element approach removes or adds the element by "killing" or "activating" the selected element in finite element analysis. In substance, the "killed" or "activated" element was not deleted or added from finite model. When the dead element was applied in analysis, stiffness matrices of the selected elements were multiplied by a reduction factor to accomplish the dead effect, which contributed to the element load, mass, damping, specific heat and other similar effects of the killed element all set to be zero, and also the element strains were set to be zero. The effect of material nonlinear was taken into consideration when nonlinear analysis was carried out by birth-to-death element method [10].

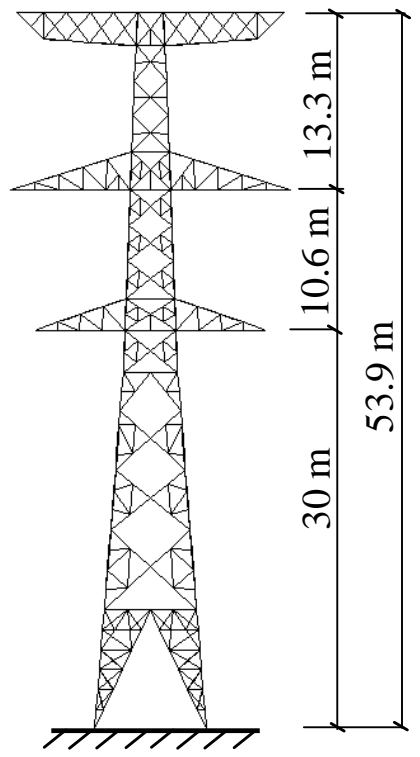

Fig. (2). The size and finite element model of the transmission tower

\subsection{Proposed Method}

In this research, the wind-induced progressive collapse of the transmission tower could be simulated by ABAQUS/Explicit, and the technique of element birth and death could be realized by writing the user subroutine VUMAT. The element would be defined as failure element, and would be removed as soon as the strain and stress of the element increased over the assigned value caused by wind loads.

\section{CALCULATION MODEL}

A three-dimensional finite element model is established with ABAQUS software based on a practical engineering in China. Fig. (2) shows the size and finite element model of the transmission tower. The height of tower is $53.9 \mathrm{~m}$, and the members of tower are simulated by B31 beam elements. The element section properties are shown in Table 1. This unit based on the theory of Timoshenko Beam Formulation allows transverse shear deformation and could analyze thick beams, and slender beam. Main members of the tower are made of Q345, and secondary members are made of Q235. The base points of the transmission tower are fixed on the ground.

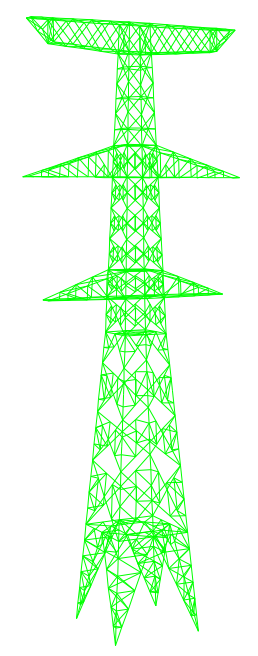


Table 1. Element section properties.

\begin{tabular}{|c|c|c|c|}
\hline Material & Beam section & Material & Beam section \\
\hline \hline Q235 & $\angle 100 \times 100 \times 8$ & Q345 & $\angle 100 \times 100 \times 8$ \\
\hline Q235 & $\angle 40 \times 40 \times 4$ & Q345 & $\angle 125 \times 125 \times 10$ \\
\hline Q235 & $\angle 45 \times 45 \times 4$ & Q345 & $\angle 160 \times 140 \times 10$ \\
\hline Q235 & $\angle 50 \times 50 \times 5$ & Q345 & $\angle 180 \times 180 \times 14$ \\
\hline Q235 & $\angle 56 \times 56 \times 5$ & Q345 & $\angle 200 \times 200 \times 14$ \\
\hline Q235 & $\angle 63 \times 63 \times 5$ & Q345 & $\angle 75 \times 75 \times 6$ \\
\hline Q235 & $\angle 70 \times 70 \times 6$ & Q345 & $\angle 80 \times 80 \times 6$ \\
\hline Q235 & $\angle 75 \times 75 \times 6$ & Q345 & $\angle 90 \times 90 \times 8$ \\
\hline Q235 & $\angle 80 \times 80 \times 7$ & & \\
\hline Q235 & $\angle 90 \times 90 \times 7$ & & \\
\hline
\end{tabular}

\section{WIND LOAD SIMULATION}

Wind is the movement of air relative to the surface. It includes mean wind and turbulent wind. In accordance with the statistical data, exponent function or logarithmic function related to the height is often used to express the mean wind [11]. Because transmission tower is very high, the logarithmic function is used and can be expressed as

$\bar{v}(z)=\frac{1}{k} u_{*} \ln \left(z / z_{0}\right)$

where, $\mathrm{z}$ is the standard height. $\mathrm{k}$ is the Karman constant equaling to 0.4. $\bar{v}(z)$ is the mean wind speed at the height of z. $z_{0}$ is the surface roughness length $(\mathrm{m}) . u_{*}$ is the friction velocity.

Because the height of tower is very high, Kaimal fluctuating wind power spectrum should be adopted when turbulent wind is simulated. Kaimal fluctuating wind power spectrum is expressed as

$\frac{n S_{v}(n)}{u_{*}}=\frac{200 x}{(1+50 x)^{5 / 3}}$

where, $x=1200 n / \bar{v}_{10} \cdot u_{*}$ is the friction velocity. $\bar{v}_{10}$ is the wind speed of standard height. $n$ is the frequency of pulse wind.

The method of harmony superposition, a discrete simulation method to simulate the steady random process, is a discrete simulation method to approach the target stochastic process adopting the discrete spectrums [12, 13]. Random signal can be divided into a series of sinusoidal waves or other harmonic waves with different amplitude and frequency through discrete Fourier transform.

According to the theory of Shinozuka, when $\mathrm{N} \rightarrow \infty$, velocity time series of fluctuating wind $u_{i}(t)$ can be obtained by

$$
u_{i}(t)=\sum_{l=1}^{i} \sum_{k=1}^{N}\left|H_{i l}\left(\omega_{k}\right)\right| \sqrt{2 \Delta \omega_{k}} \cos \left[\omega_{k} t-\theta_{i l}\left(\omega_{k}\right)+\varphi_{l k}\right] \quad i=1,2, \ldots, m
$$

where, $\mathrm{N}$ is the division numbers of fluctuating wind frequency. $H_{i l}$ is obtained from Cholesky decomposition of the wind cross-spectral density matrix. $\theta_{i l}(\omega)$ is the phase angle between the two different loading points. $\varphi_{l k}$ is the uniformly random numbers in $[0,2 \pi] . \Delta \omega_{k}$ is the frequency increment. $\omega_{k}=k \Delta \omega_{k}-\frac{N-l}{N} \Delta \omega_{k}$.

In this paper, material characteristics of transmission tower in wind field are considered. Based on the above method, Kaimal fluctuating wind power spectrum and the harmony superposition method are used to simulate the turbulent wind. The transmission tower is divided into 11 regions as shown in Fig. (3). The height of sectional points and the wind area are shown in Table $\mathbf{2}$. The fluctuating wind speed time histories of all positions are simulated, and the mean wind speeds at the $10 \mathrm{~m}$ height are $39 \mathrm{~m} / \mathrm{s}, 46 \mathrm{~m} / \mathrm{s}$ and $64 \mathrm{~m} / \mathrm{s}$, respectively. Fig. (4) shows a simulated fluctuating wind speed at point 5 and 10 with mean wind speed of 39 $\mathrm{m} / \mathrm{s}$.

In order to verify the reliability of the fluctuating wind speed time history, the simulated spectrum is compared with the target spectrum. As shown in Fig. (5), the spectral line trend of simulated spectrum is very close to target spectrum's, which illustrates the simulation method is reasonable.

The along-wind loads is given by

$$
F(t)=\frac{\mu_{s} A V(t)^{2}}{1.6}
$$

where, $\mathrm{A}$ is the area acted by wind in Table 2. $\mu_{s}$ is the shape coefficient and equal to 2.5 based on the code. $V(t)$ is the wind speed of simulation point. 


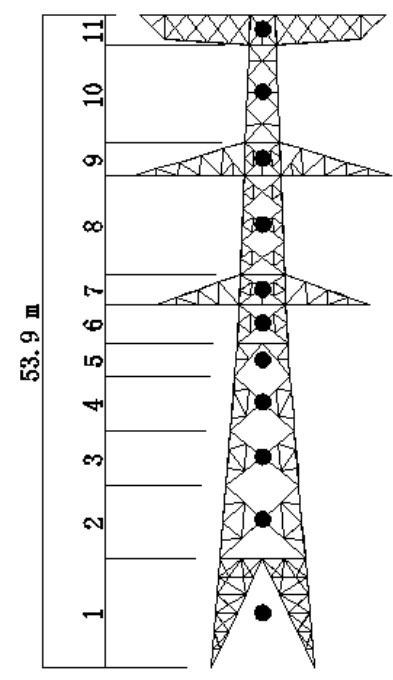

Fig. (3). The subsection of transmission tower.

\section{COLLAPSE ANALYSIS OF THE TRANSMISSION TOWER}

\subsection{The angle of attack}

The wind direction and flow speeds change with time and space. Wind angle of attack has a significant effect on the response of transmission tower [14]. In order to obtain the

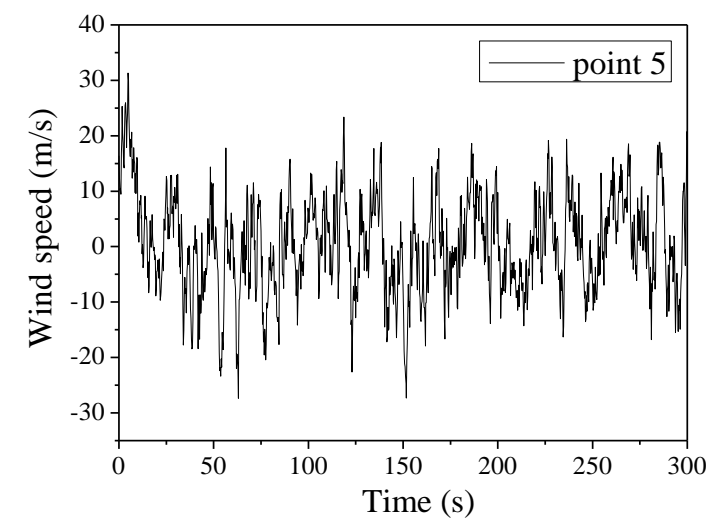

Fig. (4). The simulated fluctuating wind time history of point 5 and 10 .

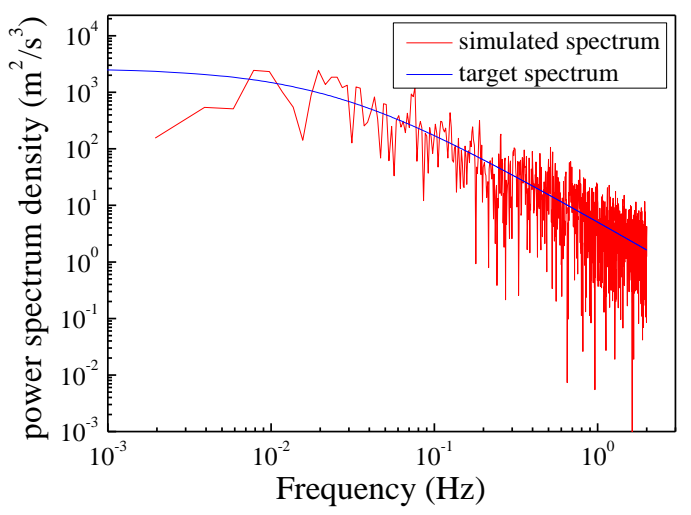

(a) Simulation point 5

Fig. (5). Comparison between simulated and objective wind spectra. collapse mode of the transmission tower under several typical wind excitations, three different angles of attack $\alpha=0^{\circ}, 45^{\circ}$ and $90^{\circ}$ are considered in the paper, respectively. The different angles of attack are shown in Fig. (6).

\subsection{Collapse analysis of the transmission tower under different angles of attack}

Birth-to-death element technique in ABAQUS/Explicit is adopted to simulate the collapse of the transmission tower. The collapse routes under different angles of attack are shown in Figs. (7, 8 and 9), respectively. Fig. (10) shows the stress comparison of the bottom element under the three angles of attack with wind speed of $38 \mathrm{~m} / \mathrm{s}$.

As shown in Fig. (7), the transmission tower happened to collapse at 0 degree angle of attack when the mean wind speed reached $46 \mathrm{~m} / \mathrm{s}$. At $0.23 \mathrm{~s}$, the main members and the secondary members in the height of $13 \mathrm{~m}$ reached or exceeded the yield strength of the material. These elements satisfied death rule and were deleted. These elements lost load carrying which caused redistribution of loads, and the elements were deleted from the middle to up and down. At $0.31 \mathrm{~s}$, the vertical load transfer path of tower was completely destroyed.

The progressive collapse of the transmission tower at $45^{\circ}$ angle of attack with the mean wind speed reaching $39 \mathrm{~m} / \mathrm{s}$ can be seen in Fig. (8). At $0.3 \mathrm{~s}$, the elements on the height of
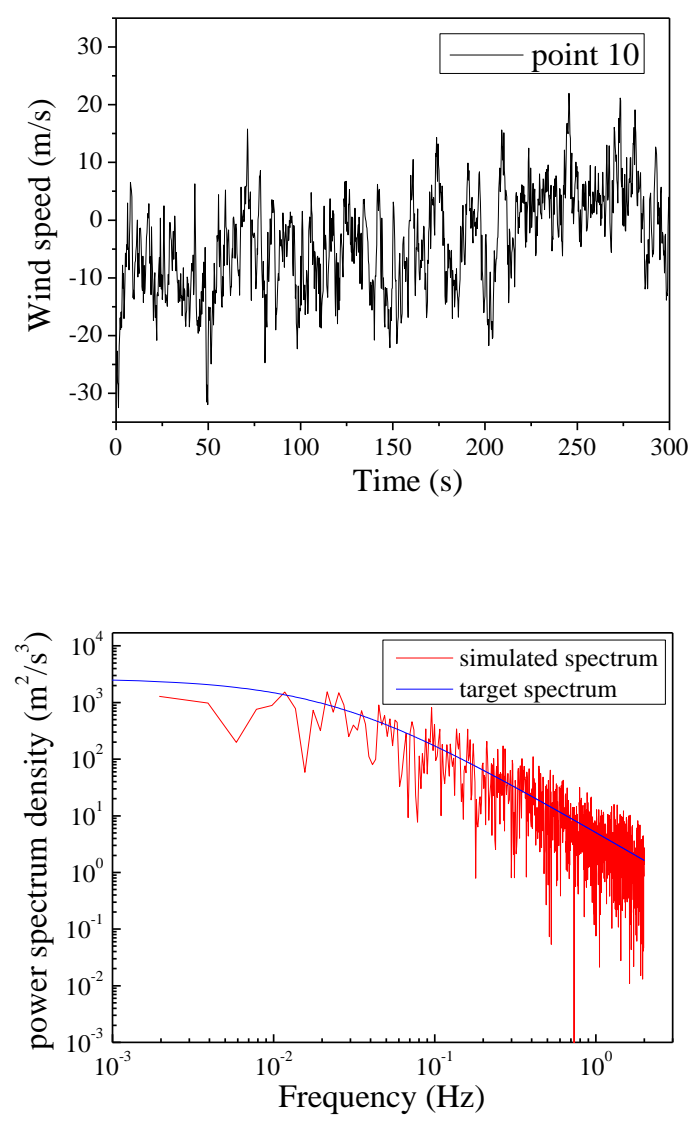

(b) Simulation point 10 
Table 2. The position of load and wind area.

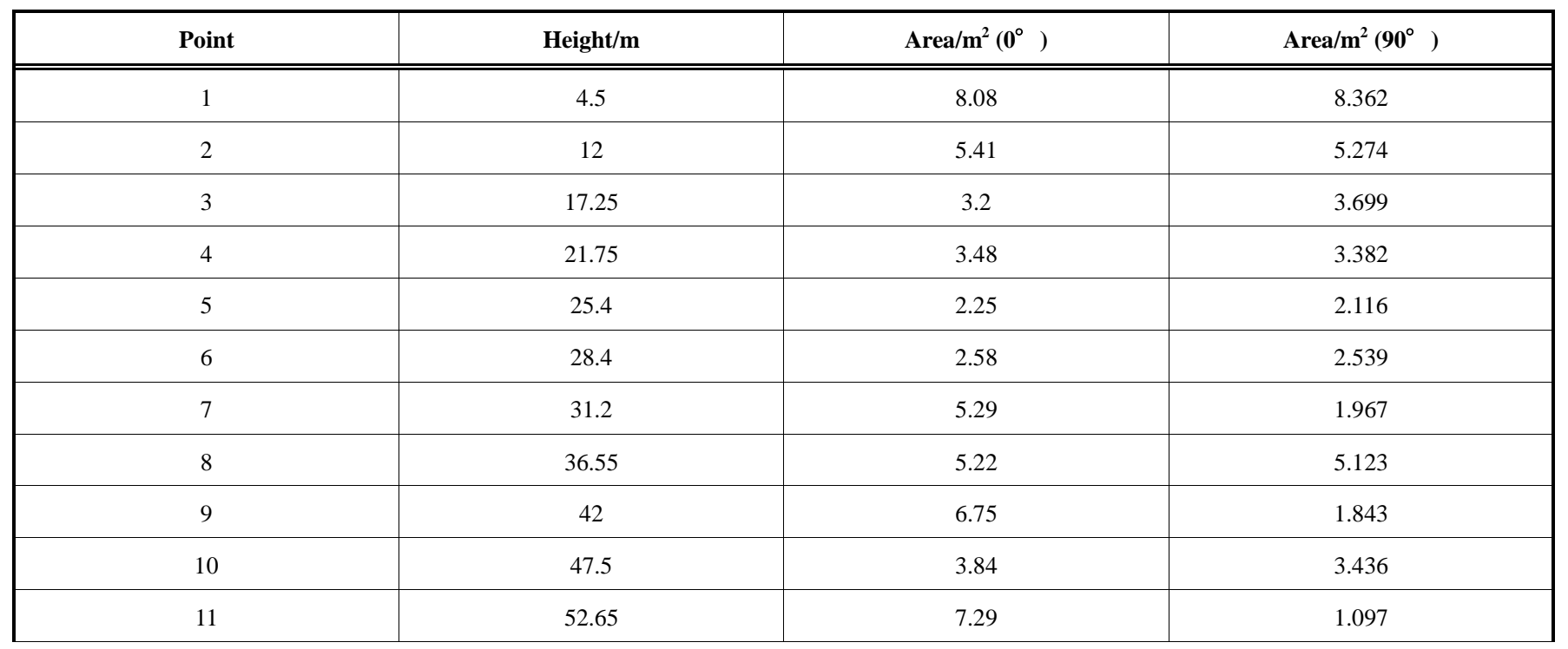

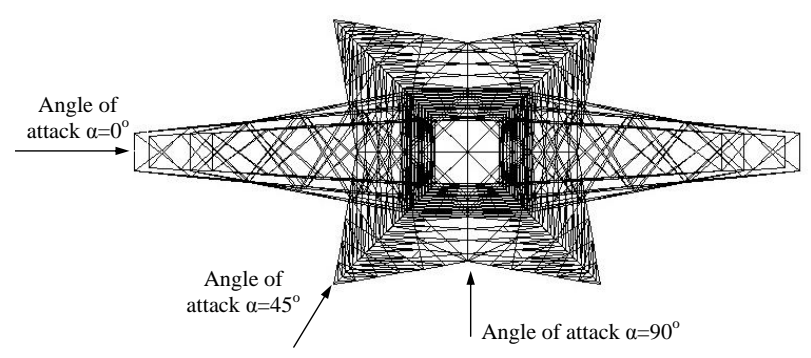

Fig. (6). The angle of attack.

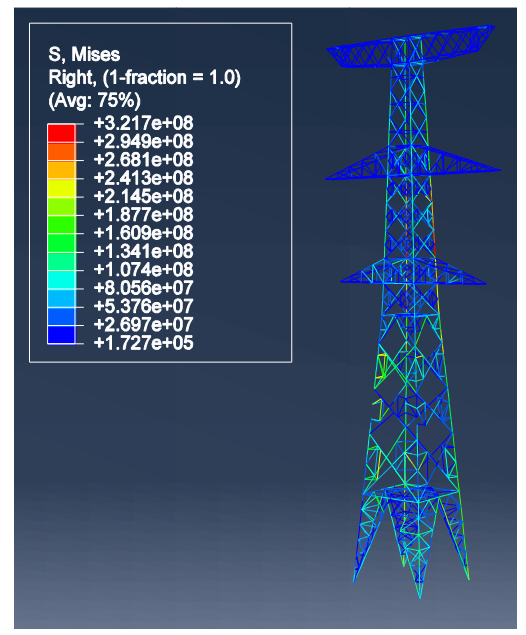

(a) $\mathrm{t}=0.23 \mathrm{~s}$

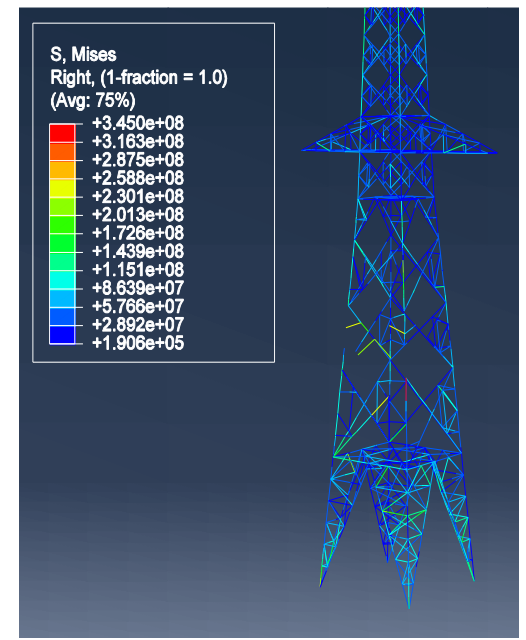

(b) $\mathrm{t}=0.25 \mathrm{~s}$

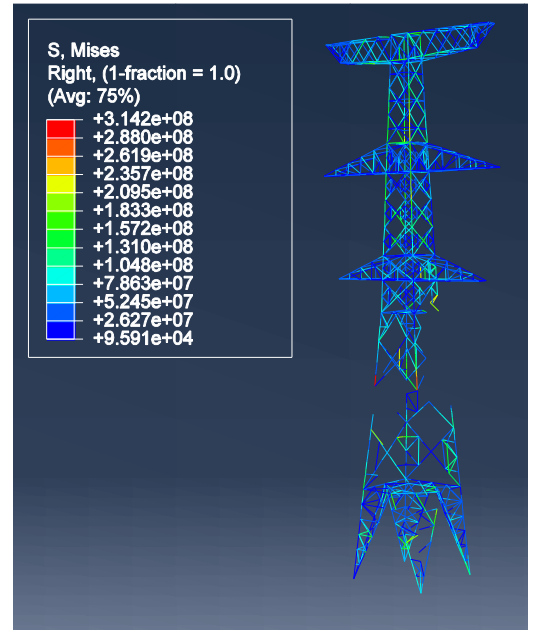

(c) $\mathrm{t}=0.31 \mathrm{~s}$

Fig. (7). The progressive collapse of the transmission tower at 0 degree angle of attack.

$12 \mathrm{~m}$ reached or exceeded the yield strength of the material and happened to destroy. Then the elements nearby damaged one after another. At the time of $0.40 \mathrm{~s}$, structure entered the rapid collapse stage with the destruction of vertical load transfer path.

Fig. (9) shows the progressive collapse of the transmission tower at 90 degree angle of attack with the mean wind speed reaching $64 \mathrm{~m} / \mathrm{s}$. At $0.24 \mathrm{~s}$, the main element on the height of $37 \mathrm{~m}$ damaged firstly. The main members and the secondary members on the height of $10 \mathrm{~m}$ were destroyed at $0.26 \mathrm{~s}$. Then the elements near the two positions reached the yield strength of the material. At $0.30 \mathrm{~s}$, the failures of these elements lead to the collapse of the transmission tower.

Fig. (10) indicated that the stress under $45^{\circ}$ angle of attack is bigger than the other two angles with the same wind speed, and the stress under $90^{\circ}$ angle of attack is minimum. The stress under $45^{\circ}$ angle of attack increase by $25.8 \%$ than 


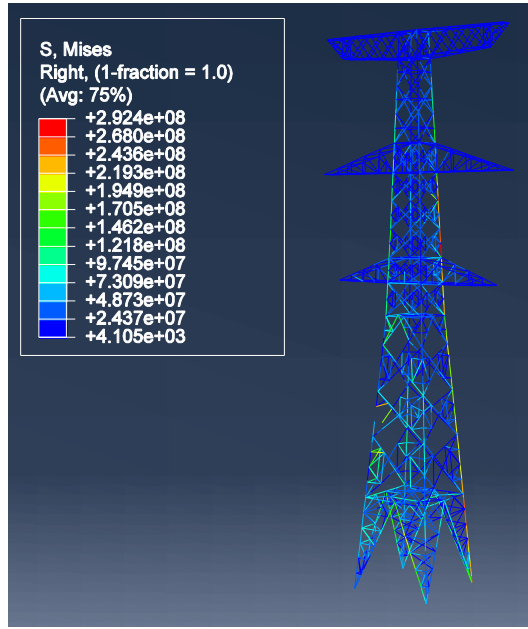

(a) $\mathrm{t}=0.3 \mathrm{~s}$

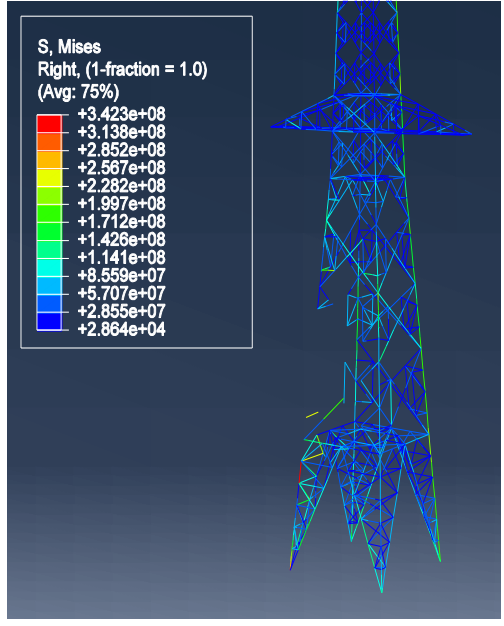

(b) $\mathrm{t}=0.31 \mathrm{~s}$

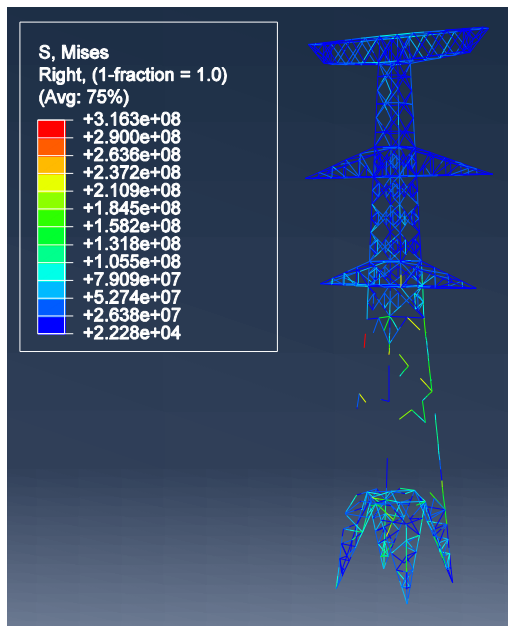

(c) $\mathrm{t}=0.40 \mathrm{~s}$

Fig. (8). The progressive collapse of the transmission tower at $45^{\circ}$ angle of attack.

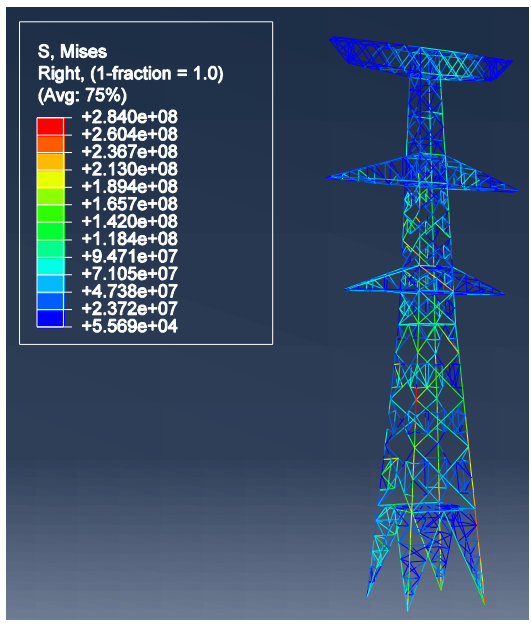

(a) $\mathrm{t}=0.24 \mathrm{~s}$

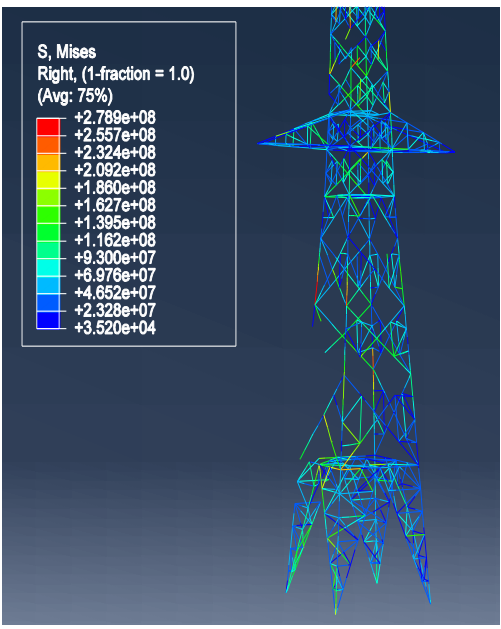

(b) $\mathrm{t}=0.26 \mathrm{~s}$

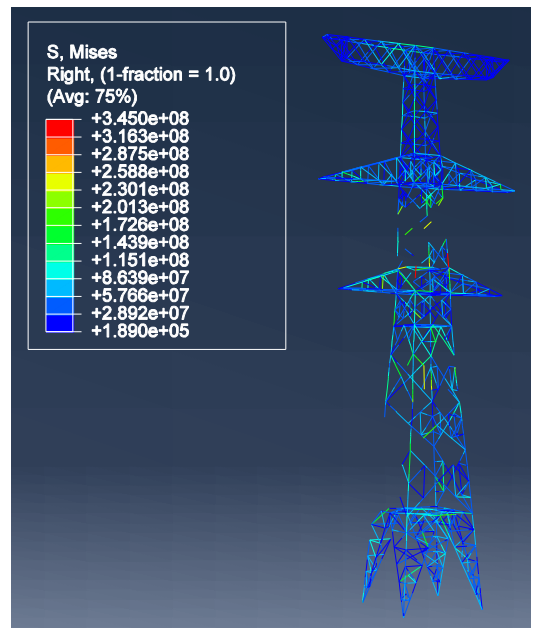

(c) $\mathrm{t}=0.30 \mathrm{~s}$

Fig. (9). The progressive collapse of the transmission tower at $90^{\circ}$ angle of attack.

that of under $0^{\circ}$ angle of attack and is $116 \%$ larger than that of under $90^{\circ}$ angle of attack. It is consistent with the results of collapse analysis.

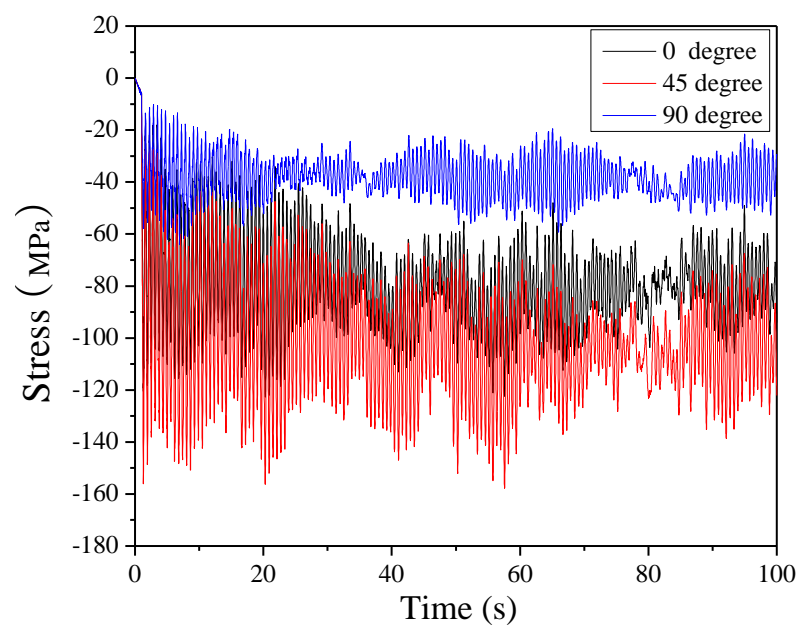

Fig. (10). The stress comparison of the bottom element with wind speed of $38 \mathrm{~m} / \mathrm{s}$.
Based on the above results, the collapse of the transmission tower at $45^{\circ}$ angle of attack happens easily, but it is contrary at $90^{\circ}$ angle of attack. The fracture position is approximately same and close to the height of $12 \mathrm{~m}$. The height of $37 \mathrm{~m}$ is also a fracture position at $90^{\circ}$ angle of attack. The main element and the secondary element lost load-bearing capability simultaneously in the initial fracture position. The collapse of the tower occurred due to the loss of one or more load-carrying elements.

\section{CONCLUSION}

The three-dimensional finite element model is established in the paper. The wind-induced progressive collapse of the transmission tower is studied using the birthto-death element technique in ABAQUS/Explicit. Based on the analysis results, the following conclusions are drawn:

(1) The birth-to-death technique in ABAQUS/Explicit is carried out, and it could be effective to execute a complex and nonlinear structural dynamics analysis. It is important to advance the structural ability in resisting collapse.

(2) According to the analysis, the fracture position could be 
obtained under wind action. The main element and the secondary element lost load-bearing capability simultaneously in the initial fracture position, which caused redistribution of loads. Then the elements nearby damaged one after another and the structure entered the rapid collapse stage.

(3) The collapse of transmission tower occurs easily at 45 degree angle of attack, but it is contrary at 90 degree angle of attack. Because the stress of element at 45 degree angle of attack is larger than that at the other two degrees with the same wind velocity, which is caused by the difference of the wind area.

The result of collapse analysis can provide reference to the design of transmission tower and the reinforcement of current structure. The wind-induced collapse of different kinds of towers and transmission tower-line systems under different attack angles should be investigated in further research.

\section{CONFLICT OF INTEREST}

The authors confirm that this article content has no conflict of interest.

\section{ACKNOLEDGMENTS}

This work is financially supported by the Ph.D. Programs Foundation of Ministry of China Project under No. 20120131120036, the Shandong Province Natural Science Foundation of China under No. ZR2012EEQ005 and Special Fund from Post Doctor Innovation Research Program of Shandong Province Post under No. 201203064. This support for research is greatly appreciated.

\section{REFERENCES}

[1] L.R. Xiang, "Speed up earlier UHV transmission research in China," Power Sys. Tech., vol. 20, pp. 54-58, February 1996. (In Chinese).

[2] R. C. Battista, R. S. Rodrigues, and M. S. Pfeil, "Dynamic behavior and stability of transmission line towers under wind forces," $J$. Wind Eng. Ind. Aerodyn., vol. 91, pp.1051-1067, August 2003.

[3] T. Okamura, T. Ohkuma, E. Hongo, and H. Okada, "Wind response analysis of a transmission tower in a mountainous area," J. Wind Eng. Ind. Aerodyn., vol. 91, pp. 53-63, January 2003.

[4] L. L. Zhang, Q. Xie, and J. Li, "Dynamic wind-induced response analysis of multi-tower-line coupled system of transmission line," J. Disast. Preven. Mitigation Eng., vol. 26, pp. 61-267, August 2006. (In Chinese).

[5] X. M. Yan, M. J. He, and G. H. Li, "Transmission line system dynamic response analysis on influence parameters," Henan Sci., vol. 28, pp. 561-565, May 2010. (In Chinese).

[6] L. Qin, J. J. Yuan, and W. Li, "Random wind-induced response analysis of transmission tower-line system," In International Conference on Future Energy, Environment, and Materials, 2012, pp. 1813-1821.

[7] T. G. Mara, and H. P. Hong, "Effect of wind direction on the response and capacity surface of a transmission tower." Eng. Struct., vol. 57, pp. 493-501, November 2013.

[8] L. Tian, R. S. Ma, W. M. Wang, and L. Wang, "Progressive Collapse Analysis of Power Transmission Tower Under Earthquake Excitation,” Open Civil Eng. J., vol. 7, pp. 164-169, August 2013.

[9] W. M. Wang, H. N. Li, and L. Tian, "Progressive collapse analysis of transmission tower-line system under earthquake," Adv. Steel Construct., vol. 9, pp. 161-172. June 2013.

[10] J. Zheng, H. P. Ge, X. T. Wang, Z. He, and Y. Luo, "A method of element birth and death of local constraint and its application in construction configuration mechanics," J. Building Struct., vol. 33, pp. 101-108, August 2012. (In Chinese).

[11] X. T. Zhang, Structural wind engineering. China building industry press, 2006. (In Chinese).

[12] M. Shinozuka, "Simulation of multivariate and multidimensional random processes," Acoust. Soc. Am. vol. 49, pp. 357-368, 1971.

[13] M. Shinozuka, and C. M. Jan, "Digital simulation of random processes and its applications," J. Sound and Vibr., vol. 25, pp.111128, November 1972.

[14] H. Z. Deng, R. J. Si, X. Y. Hu, and Q. Chen, "Wind tunnel test on aeroelastic model of UHV latticed transmission tower," J. Tongji Univ. (Natural Science), vol. 38, pp.673-678, May 2010. (In Chinese). 